\title{
Influence of Annealing Time on $\Sigma 3$ Boundary and $\Sigma 9$ Boundary Evolutions in Hastelloy C-276 Alloy
}

\author{
Zhang Xiaoyu ${ }^{1}{ }^{1,}, \quad$ Li Defu ${ }^{1}, \quad$ Guo Shengli ${ }^{1}, \quad$ Zhao Xianming ${ }^{2}$ \\ ${ }^{1}$ Beijing General Research Institute for Nonferrous Metals, Beijing 100088, China; ${ }^{2}$ State Key Laboratory of Rolling and Automation, \\ Northeastern University, Shenyang 110004, China
}

\begin{abstract}
Hastelloy C-276 was subjected to low strain deformation and then annealed at $1100{ }^{\circ} \mathrm{C}$ for different time. The $\Sigma 3$ and $\Sigma 9$ boundary percentages and grain boundary plane distributions were characterized by electron back-scatter diffraction (EBSD) and a five-parameter analysis method. The results show that the $\Sigma 3$ boundary evolves towards a more exact coincident-site lattice (CSL) misorientation and the $\Sigma 3$ boundary plane is closer to low surface energy plane $\{111\}$ with the increasing of annealing time. This is consistent with fine tuning mechanism. While the population of incoherent $\Sigma 3$ boundary is increasing, the proportion of $\Sigma 9$ boundary with larger deviations increase, too. And the distributions of grain boundary density planes for $\Sigma 9$ boundary are more intensive on the whole [110] zone.
\end{abstract}

Key words: Hastelloy C-276; $\Sigma 3$ and $\Sigma 9$ boundary; grain boundary plane distribution; EBSD

Hastelloy C-276 alloy is a Ni-Cr-Mo alloy that is generally regarded as a versatile corrosion-resistant alloy. Due to its good high temperature strength, high resistance to neutron radiation and corrosive environment abilities, it has been widely used in chemical, oil and nuclear industries ${ }^{[1,2]}$. In particular, Hastelloy C-276 is being selected as a potential candidate material in construction of different components of Gen IV reactors ${ }^{[3]}$. However, to be suitable for the Gen IV designed environment, some modifications of material's structure should be considered. The present reports ${ }^{[4,5]}$ state that grain boundary characteristics strongly affect the properties of material.

Grain boundary engineering (GBE) is a method of manipulating the grain boundaries in a microstructure so that a higher fraction of 'special' boundaries is obtained. The 'special' boundaries are essentially low sigma coincident-site lattice (CSL) boundaries. These boundaries are different from random high angle boundaries in properties of grain boundary energy and migration. The 'special' boundaries are brought about by suitable thermos-mechanical processing in body centred cubic materials. Grain boundary engineering can improve material properties like ductility, corrosion and oxidation resistance, creep and fracture resistance ${ }^{[5,6]}$.

Grain boundary properties depend on both the lattice misorientation and the orientation of the grain boundary plane $^{[7]}$. Grain boundaries with low-index surfaces have relatively low energies. The observations suggest ${ }^{[8]}$ that a 'special' grain boundary should be defined as one that is terminated by at least one low-index plane. Saylor et al. ${ }^{[9]}$ have developed a stereological procedure to determine the distribution of boundary planes from orientation maps on single planar sections. This technique, known as fiveparameter analysis, coupled with automated trace analysis software was used to extract the five-parameter distribution from EBSD maps. The five-parameter area distributions are expressed as 'multiples of a random distribution' (MRD).

The aim of the present report was to investigate the evolutions of $\Sigma 3$ and $\Sigma 9$ boundaries with annealing time. We employ the five-parameter stereology to reveal the distributions of $\Sigma 3$ and $\Sigma 9$ grain boundary plane orientations in Hastelloy C-276 annealed for different time. The data will be interpreted with the distribution of boundary planes and its

Received date: November 25,2015

Foundation item: National Natural Science Foundation of China (50834008)

Corresponding author: Zhang Xiaoyu, Ph. D., Beijing General Research Institute for Nonferrous Metals, Beijing 100088, P. R. China, Tel: 0086-10-61771755, E-mail: xy12152006@126.com

Copyright (C) 2016, Northwest Institute for Nonferrous Metal Research. Published by Elsevier BV. All rights reserved. 
consequences for our understanding of the $\Sigma 3$ and $\Sigma 9$ boundary evolutions.

\section{Experiment}

$1 \mathrm{~mm}$ thick Hastelloy C-276 sheet whose chemical composition (wt\%) was $15.07 \mathrm{Cr}, 15.53 \mathrm{Mo}, 4.14 \mathrm{Fe}, 4.04 \mathrm{~W}$, 2.5 Co, 0.62 Mn, 0.01 P, 0.08 Si, 0.012 C, 0.002 S and Bal. Ni, was solution-heat treated at $1150{ }^{\circ} \mathrm{C}$ for $0.5 \mathrm{~h}$ and then used for processing. The samples were cold rolled with thickness reduction of $5 \%$. The cold-worked samples were afterwards annealed at $1100{ }^{\circ} \mathrm{C}$ for $0.25 \sim 1 \mathrm{~h}$.

The surfaces of samples were firstly ground with $\mathrm{SiC}$ and diamond abrasives, then they were electropolished in an electrolyte containing $\mathrm{H}_{2} \mathrm{SO}_{4}: \mathrm{CH}_{3} \mathrm{COOH}=1: 4$ at room temperature. The fractions of special boundaries were determined by electron backscatter diffraction (EBSD) using a JEOL JSM7001LV SEM with EDAX (TSL) OIM Data Collection 6.0 software. The OIM analysis software was then used to extract the boundary line traces from the samples. The five-parameter grain boundary distribution (FPGBD) was determined from these traces using a procedure described previously ${ }^{[9]}$. Part of the procedure was segmentation of curved grain boundaries. The Brandon Criterion ${ }^{[10]}$ was used to classify CSL boundaries, as a fraction of total boundary length. The proportion of misorientations on specific axes ([110], [111]) was calculated with a tolerance of $\pm 5^{\circ}$. The resolution of the distribution is approximately $10^{\circ}$ and all distributions are plotted in stereographic projection.

\section{Results}

\subsection{Fractions of $\Sigma 3$ boundary and $\Sigma 9$ boundary}

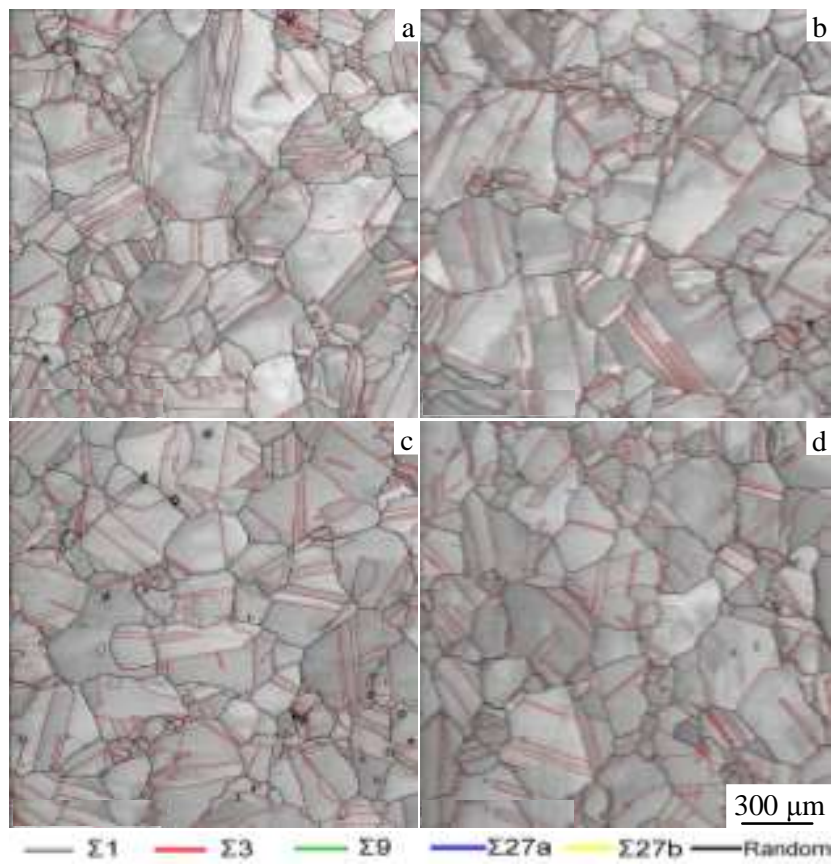

Fig.2 Grain boundary images of quality (IQ) map of $5 \%$ strain annealed at $1100{ }^{\circ} \mathrm{C}$ for various time: (a) $5 \mathrm{~min}$, (b) $15 \mathrm{~min}$, (c) $30 \mathrm{~min}$, and (d) $60 \mathrm{~min}$
As shown in Fig. 1 we can see that the fraction of $\Sigma 3$ boundary increases from $58.7 \%$ to $60.2 \%$ as the time is prolonged to $15 \mathrm{~min}$. After that, the fraction falls to $57 \%$. There is a peak percentage at $15 \mathrm{~min}$. The trend illustrates that any longer annealing time cannot affect the increase of $\Sigma 3$ boundary, the rational processing should be adapted with right time. The conclusions are consistent with the results of S. L. Lee researches ${ }^{[11]}$. The $\Sigma 9$ boundary percentage is less than $3 \%$. There are small changes with increasing annealing time. However, the tendency of $\Sigma 9$ boundary does not correspond to the tendency of $\Sigma 3$ boundary, because the peak percentage of the $\Sigma 9$ boundary is at $30 \mathrm{~min}$. This may be due to the reaction of the boundaries: $\Sigma 3+\Sigma 3 \rightarrow \Sigma 9$.

The EBSD map of the 5\% thickness reduction annealed at $1100{ }^{\circ} \mathrm{C}$ for different time is shown in Fig.2. The $\Sigma 3$ boundaries are colored red lines. They indicate that the main boundaries are

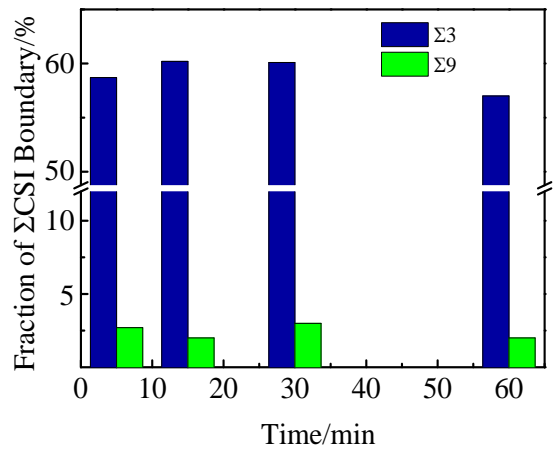

Fig.1 Fractions of $\Sigma 3$ boundary and $\Sigma 9$ boundary of Hastelloy C-276 annealed at $1100{ }^{\circ} \mathrm{C}$ for different time 
$\Sigma 3$ boundaries, and most of them are in the shape of a straight single line or parallel line pairs within grains. And few island and curved incoherent $\Sigma 3$ boundaries are obtained in these maps. The microstructure consists of equiaxed grains ranging between $30 \mu \mathrm{m}$ and $260 \mu \mathrm{m}$ in size as shown in Fig.2a. With extended time, the average grain size has a small decrease from $101 \mu \mathrm{m}$ to $89 \mu \mathrm{m}$ (Fig.2d).

\subsection{Evolutions of $\Sigma 3$ boundary and $\Sigma 9$ boundary plane during annealing}

In all of the projections, the [001] crystal axis is perpendicular to the plane of the paper and the [100] direction is horizontal in the plane of the paper, pointing to the right. The distributions of $\Sigma 3$ boundary plane are plotted in standard stereographic projection in Fig.3. The relative areas of $\Sigma 3$ boundary planes are centred on $\{111\}$ planes. And they show a preference for $\langle 111\rangle$ misorientation axes twist boundaries. The MRD values are not increased with the increasing of annealing time in Fig.3. On the contrary, the maximum proportion of $\Sigma 3$ boundary is in the sample annealed at $15 \mathrm{~min}$ and the MRD valves are not the peak. It illustrates that many $\Sigma 3$ boundaries cannot terminate on $\{111\}$ plane, and there are a lot of incoherent $\Sigma 3$ boundaries in the sample annealed for $15 \mathrm{~min}$.

The distributions of grain boundary density planes for $\Sigma 9$ $\left(39^{\circ} /[110]\right)$ section annealed at $1100{ }^{\circ} \mathrm{C}$ for various time are shown in Fig. 4. In the section for $\Sigma 9$ there are multiple peaks on the [110] zone. The predominant maxima along the [110] zone indicate that most of the segments have a tilt character. Note that the maximum along the tilt zone is found at the tilt boundary (114) in Fig.4a. However, the maximum MRD values on the [110] zone are at the symmetric (221) and ( $\overline{1} \overline{1} 2)$ in Fig.4b. For extended time, the maximum along the tilt zone is more intensive on the whole [110] zone. The maxima appear to be confined more narrowly on the [110] zone.

The change in proximity factor for the $\Sigma 3$ boundary with the increasing of annealing time can be rationalized as an overall reduction of accumulated strains in the microstructure, which are associated with local lattice rotations. The $\Sigma 3$ boundary deviations are small with the increasing of annealing time, and this is reported ${ }^{[12]}$ by Thomson in the annealing process of strain-annealed nickel. And the $\Sigma 9$ boundary deviations are very larger for annealing periods of 15 and $30 \mathrm{~min}$. This is closely related to the interactions of $\Sigma 3^{\mathrm{n}}$ boundaries.

\section{Discussions}

In Fig.1, the peak of $\Sigma 3$ boundary percentage is in the sample annealed at $15 \mathrm{~min}$, whereas the MRD values of $\{111\}$ planes decrease in Fig.3b. The decrease of MRD values in $\{111\}$ planes indicates most of the additional $\Sigma 3$ population is incoherent twins, because coherent annealing twins would have been on $\{111\}$. According to the paper results ${ }^{[13]}$, a coherent twin and one vicinal-to- $\{111\} \Sigma 3$ (incoherent twin) boundary meet at a triple junction generated $\Sigma 9$ boundaries with high deviations. While the population of incoherent $\Sigma 3$ boundary is increasing, the larger deviations $\Sigma 9$ boundary proportion also increases. It can be seen from Fig.5 and Fig.6, the MRD values of $\Sigma 9$ boundary planes are lower and the deviations of $\Sigma 9$ boundaries are larger for annealing periods of 15 and $30 \mathrm{~min}$.
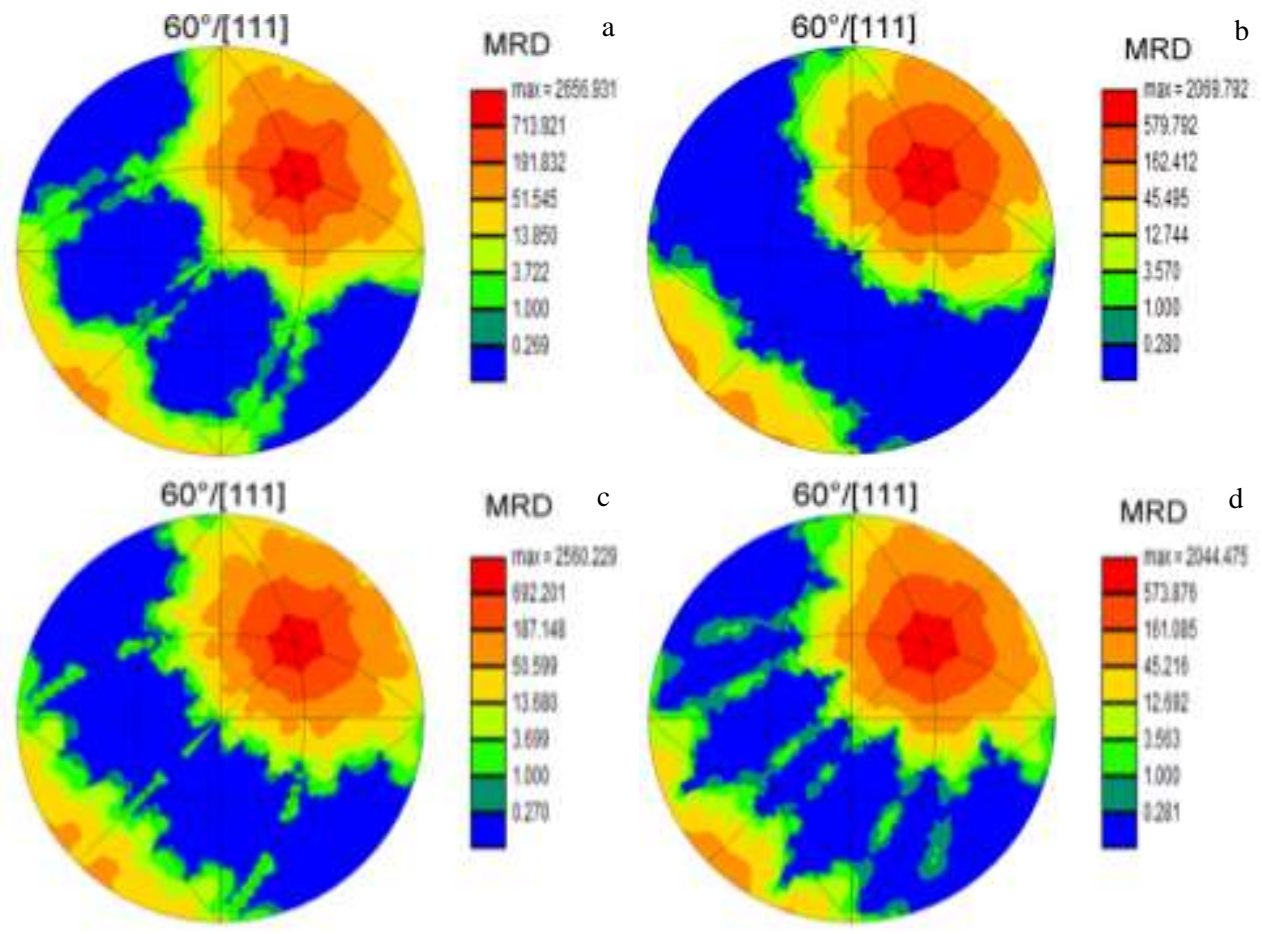

Fig.3 Distributions of grain boundary density planes for $\Sigma 3\left(60^{\circ} /[111]\right)$ section annealed at $1100{ }^{\circ} \mathrm{C}$ for various time: (a) $5 \mathrm{~min}$, (b) $15 \mathrm{~min}$, (c) $30 \mathrm{~min}$, and (d) $60 \mathrm{~min}$ 

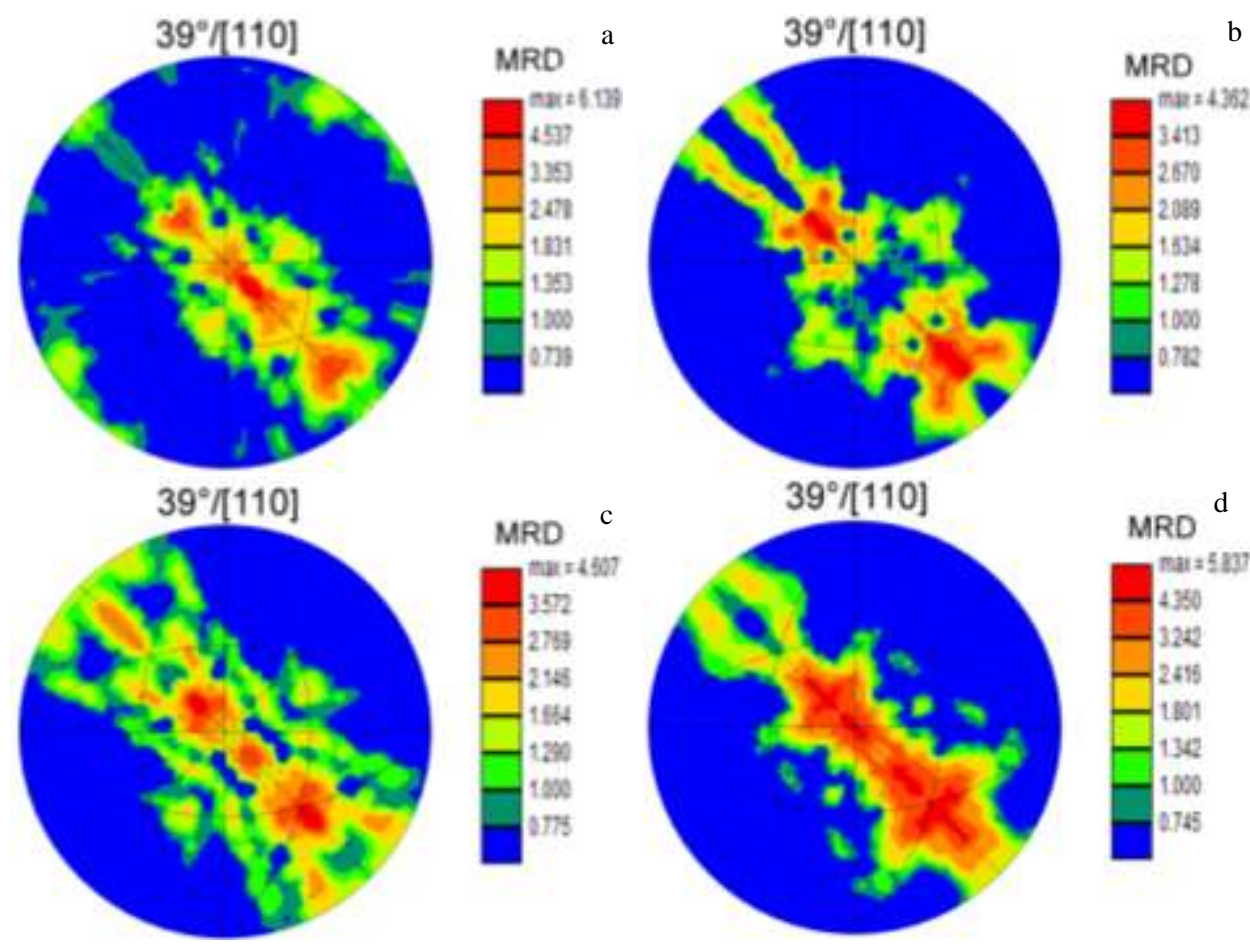

Fig.4 Distributions of grain boundary density planes for $\Sigma 9\left(39^{\circ} /[110]\right)$ section annealed at $1100{ }^{\circ} \mathrm{C}$ for various time: (a) $5 \mathrm{~min}$, (b) $15 \mathrm{~min}$, (c) $30 \mathrm{~min}$, and (d) $60 \mathrm{~min}$
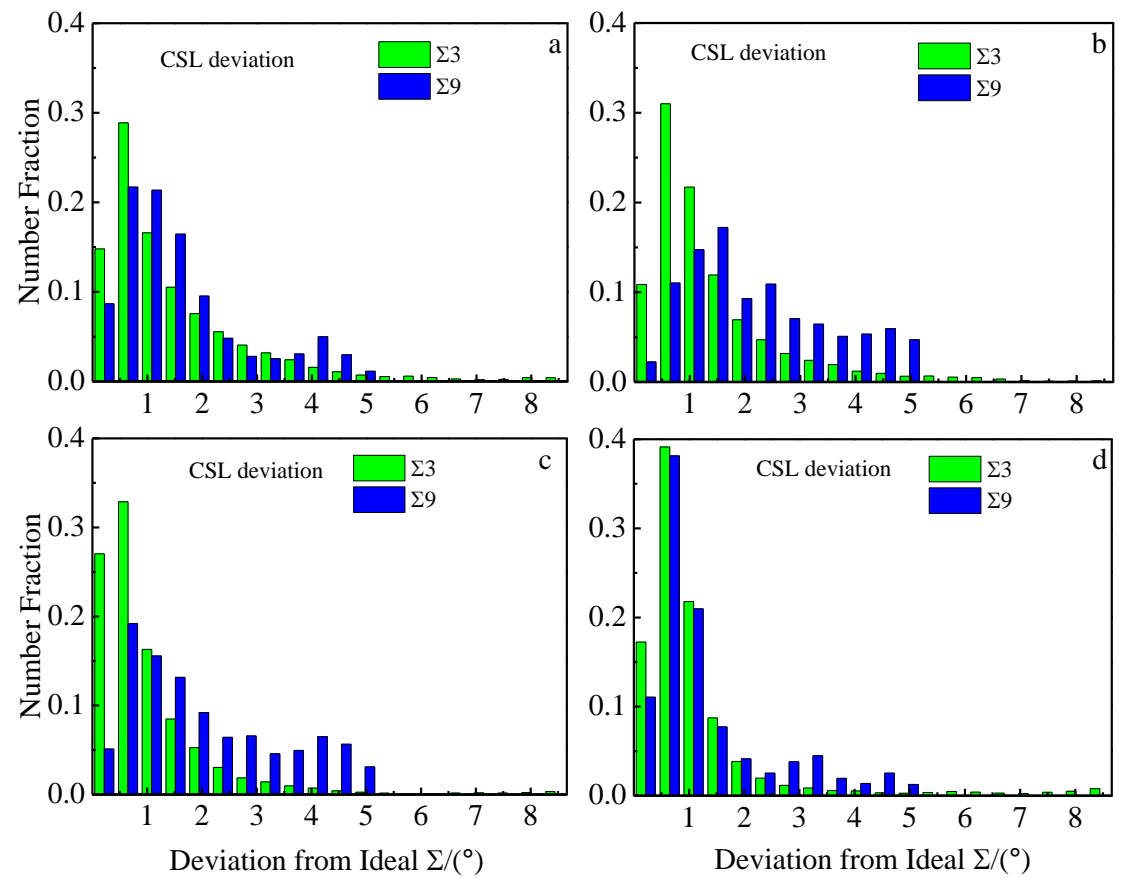

Fig.5 Number fraction of $\Sigma 3$ boundary and $\Sigma 9$ boundary deviations from ideal $\Sigma$ CSL boundaries at different annealing time:

(a) $5 \mathrm{~min}$, (b) $15 \mathrm{~min}$, (c) $30 \mathrm{~min}$, and (d) $60 \mathrm{~min}$

The most common plane presented in nickel-based materials is the plane with the lowest surface energy, $\{111\}$. This tendency for boundaries to terminate on low surface energy planes has been observed in face-centred cubic materials, and the dominance of $\{111\}$ boundary planes has been recorded in nickel specimens ${ }^{[14]}$. Hence, the $\Sigma 3$ boundary evolves towards a more exact CSL misorientation during annealing. The present data further confirm this preponderance of low surface energy planes as a general trend, as shown in Fig.6. That explains the proportion of coherent $\Sigma 3$ boundaries 


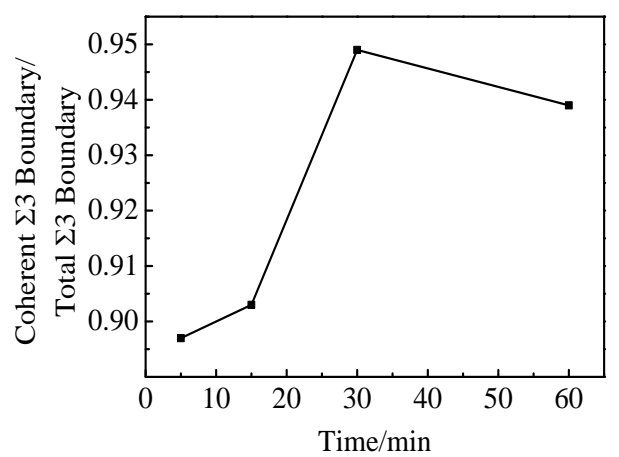

Fig.6 Change of ratio (coherent $\Sigma 3$ boundary/total $\Sigma 3$ boundary) with annealing time

(the deviations from the reference misorientation are $\leq 3^{\circ}$ ) are larger with the increasing of annealing time. This is in agreement with the fine tuning mechanisms ${ }^{[15]}$, i.e. the $\Sigma 3$ boundary evolves to closer CSL matching, and the deviation is reduced by local lattice rotation near the boundary, probably accompanied by boundary plane reorientation.

The aim of GBE is to get more 'special' grain boundaries with low surface energy planes. Prolonging annealing time is useful during the GBE processing. Applying the GBE technique to manufacture products for enhancing the grain boundary related properties is the final goal of the GBE researches.

\section{Conclusions}

1) Reasonable annealing time can promote the frequency of $\Sigma 3$ boundary increasing, and $\Sigma 3$ boundary evolves towards a more exact CSL misorientation with the increasing of annealing time. This is in agreement with the fine tuning mechanisms.

2) The proportion of $\Sigma 9$ boundary with high deviations is larger due to the increasing of incoherent $\Sigma 3$ boundary population, according to the interaction: $\Sigma 3+\Sigma 3 \rightarrow \Sigma 9$.

\section{References}

1 Akhter J I, Shaikh M A, Ahmad M et al. Journal of Materials Science Letters[J], 2001, 20(4): 333

2 Hashim M, Babu K E S R, Duraiselvam M et al. Materials \& Design[J], 2013, 46: 546

3 Zhang Q, Tang R, Yin K et al. Corrosion Science [J], 2009, 51(9): 2092

4 Watanabe T, Tsurekawa S, Kobayashi S et al. Materials Science and Engineering $A[\mathrm{~J}], 2005,410: 140$

5 Randle V. Acta Materialia[J], 2004, 52(14): 4067

6 Kobayashi S, Hirata M, Tsurekawa S et al. Procedia Engineering[J], 2011, 10: 112

7 Rohrer G S, Randle V, Kim C S et al. Acta Materialia[J], 2006, 54(17): 4489

8 Randle V. Scripta Materialia[J], 2006, 54(6): 1011

9 Saylor D M, El-Dasher B S, Adams B L et al. Metallurgical and Materials Transactions A[J], 2004, 35(7): 1981

10 Brandon D G. Acta Metall[J], 1966,14: 1479

11 Lee S L, Richards N L. Materials Science and Engineering A[J], 2005, 405(1): 74

12 Thomson C B, Randle V. Textures and Microstructures[J], 1996, 28(1): 71

13 Randle V, Hu Y. Journal of Materials Science[J], 2005, 40(12): 3243

14 Randle V, Rohrer G S, Miller H M et al. Acta Materialia[J], 2008, 56(10): 2363

15 Thomson C B, Randle V. Acta Materialia[J], 1997, 45(12): 4909

\title{
Hastelloy C-276 合金 $\Sigma 3$ 晶界和 $\Sigma 9$ 晶界随着退火时间的演变规律
}

\author{
张晓宇 ${ }^{1,2}$, 李德富 ${ }^{1}$, 郭胜利 ${ }^{1}$, 赵宪明 ${ }^{2}$ \\ (1. 北京有色金属研究总院, 北京 100088)
}

(2. 东北大学 轧制技术及连轧自动化国家重点实验室, 辽宁 沈阳 110004)

\begin{abstract}
摘 要: Hastelloy C-276 合金经小变形量冷轧后进行 $1100{ }^{\circ} \mathrm{C}$ 不同时间的退火处理。采用 $\mathrm{EBSD}$ 技术对 $\Sigma 3$ 和 $\Sigma 9$ 晶界比例进行统计, 同 时采用五参数法对 $\Sigma 3$ 和 $\Sigma 9$ 晶界面分布进行分析。结果表明, $\Sigma 3$ 晶界随着退火时间的延长更加接近于标准重合点阵晶界取向, 而其 晶界面更加接近于低能量的 $\{111\}$ 晶界面。这一结果符合晶界 “微调” 机制。 $\Sigma 9$ 晶界面分布则越来越集中在[110]晶带。而偏差较大的 $\Sigma 9$ 晶界比例增加, 是由于非共格 $\Sigma 3$ 比例的增加导致的。

关键词: Hastelloy C-276 合金; $\Sigma 3$ 和 $\Sigma 9$ 晶界; 晶界面分布; EBSD
\end{abstract}

作者简介：张晓宇, 男, 1985 年生, 博士, 北京有色金属研究总院加工事业部, 北京 100088, 电话: 010-61771755, E-mail: xy12152006@126.com 